Audiology

Neurotology
Audiol Neurotol 2013;18:383-391

DOI: $10.1159 / 000355283$
Received: May 2, 2013

Accepted after revision: August 20, 2013

Published online: November 1, 2013

\title{
Gentamicin Concentration Gradients in Scala Tympani Perilymph following Systemic Applications
}

\author{
Hartmut Hahn ${ }^{a} \quad$ Alec N. Salt ${ }^{d} \quad$ Ulrike Schumacher ${ }^{b}$ Stefan K. Plontke ${ }^{c}$ \\ ${ }^{a}$ Department of Otorhinolaryngology, Head and Neck Surgery and Tübingen Hearing Research Center (THRC) \\ and ${ }^{\mathrm{b}}$ Institute of Medical Microbiology and Hygiene, University of Tübingen, Tübingen, and ${ }^{\mathrm{C}}$ Department \\ of Otorhinolaryngology, Head and Neck Surgery, University of Halle-Wittenberg, Halle (Saale), Germany; \\ ${ }^{\mathrm{d}}$ Department of Otolaryngology, Washington University School of Medicine, St. Louis, Mo., USA
}

\section{Key Words}

Cochlea · Drug delivery · Gentamicin · Inner ear · Ototoxicity · Perilymph · Pharmacokinetics · Guinea pig

\begin{abstract}
It has been shown in prior studies that round window membrane (RWM) application of gentamicin produced a robust basal-apical concentration gradient in the perilymph of scala tympani (ST) with peak concentrations in the basal turn of ST. These gradients potentially contribute to the clinical efficacy and safety of intratympanic gentamicin applications for the treatment of Ménière's disease. The present study aimed to establish the distribution of gentamicin along ST perilymph after systemic applications. Gentamicin sulfate was applied intravenously in the amounts of 100, 300 and $600 \mathrm{mg} / \mathrm{kg}$ body weight (BW) over a period of $3 \mathrm{~h}$ or as a 300 $\mathrm{mg} / \mathrm{kg}$ BW subcutaneous bolus injection. At 3 and $5 \mathrm{~h}$ after the start of the application perilymph of ST was aspirated from the cochlea apex of the right and left cochlea, respectively, and 10 sequential $1-\mu l$ perilymph samples from the apex of each cochlea were quantitatively analyzed using a fluorescence polarization immunoassay. In contrast to local RWM delivery, systemic application of gentamicin resulted in the highest perilymph levels in the apex of the cochlea with decreasing concentrations towards the basal regions of
\end{abstract}

ST. The absolute gentamicin concentrations increased with the amount of drug applied and time before sampling. While it is likely that the basal-apical gradient measured after local drug applications to the round window niche is the result of the direct uptake of drugs into the perilymph of the ST, distribution by diffusion and a very low perilymph flow towards the cochlear apex, computer simulations suggested that the apical-basal gradient observed with these systemic applications can be explained by higher entry rates of gentamicin in the apex compared to the basal turns of the cochlea. It is also possible that gentamicin enters perilymph indirectly from the blood via the endolymph. In this case the faster kinetics in apical turns could be due to the smaller cross-sectional area of ST relative to endolymph in the apical turns.

(c) 2013 S. Karger AG, Basel

\section{Introduction}

Gentamicin is an aminoglycoside antibiotic in clinical use for the treatment of Gram-negative bacterial infections and is one of the most commonly used antibiotics worldwide. In addition to its nephrotoxicity, ototoxic side effects with sensorineural hearing loss and vertigo are well documented in both adults and children. The vestibulotoxic properties of locally applied aminoglycosides

\section{KARGER}

E-Mail karger@karger.com

www.karger.com/aud
(C) 2013 S. Karger AG, Basel

$1420-3030 / 13 / 0186-0383 \$ 38.00 / 0$
Stefan K. Plontke, MD

Department of Otorhinolaryngology - Head and Neck Surgery

University of Halle-Wittenberg, Ernst-Grube-Strasse 40

DE-06120 Halle (Saale) (Germany)

E-Mail Stefan.Plontke@uk-halle.de 
have been used for the treatment of Ménière's disease for more than half a century [Schuknecht, 1956]. In order to decrease sensorineural hearing loss initial systemic treatments have been replaced by local intratympanic injections for local drug delivery to the inner ear [Lange, 1977; Beck and Schmidt, 1978; Chia et al., 2004; Salt et al., 2008; Pullens and van Benthem, 2011].

Interpretation of early pharmacokinetic studies of gentamicin after local application to the inner ear of the chinchilla [Hoffer et al., 1997] showed that entry of drug into the vestibule does not occur by diffusion or flow along the perilymphatic scalae, passing through the helicotrema. Rather, it occurs through local communication between scalae in all segments of the cochlea with gentamicin crossing readily between scala tympani (ST) and scala vestibuli, and from there diffusing into the vestibule [Plontke et al., 2002]. The simulations also suggested that when drugs are applied to the round window membrane (RWM) they do not become uniformly distributed throughout the inner ear fluid compartments, but that the basal region of the cochlea is exposed to higher gentamicin levels than the vestibule, while apical regions of the cochlea are exposed to lower levels. These predictions were later experimentally confirmed by animal experiments quantitatively demonstrating substantial gradients of gentamicin along the length of ST after RWM application, averaging more than 4,000 times greater concentration at the base compared to the apex at the time of sampling [Plontke et al., 2007]. Recently, it has been shown that gadolinium directly enters the vestibule in the vicinity of the stapes [King et al., 2011], so the possibility that a significant proportion of gentamicin enters the ear via the stapes has to be considered. The substantial basal-apical gradients with local applications account for the observation that hair cells are predominantly lost from the basal turn [Imamura and Adams, 2003; Wagner et al., 2005]. Rapid communication between scalae and entry through the oval window in addition to the round window may partially account for the known vestibulotoxicity relative to cochlear toxicity after intratympanic gentamicin application for Ménière's disease.

When ototoxic levels of gentamicin are applied systemically, pathological changes also predominantly occur in the basal regions of the cochlea [Igarashi et al., 1971] and result in high-frequency hearing losses [Fausti et al., 1994]. However, in vitro studies where a uniform concentration of gentamicin was applied to explanted tissues also found that hair cells from the basal and middle cochlea turns were more susceptible to damage by gentamicin than those from apical turns [Sha et al., 2001; Alharaz- neh et al., 2011]. Thus, the presence of high-frequency hearing loss or differences in hair cell losses between basal and apical turns gives no indication of whether gentamicin concentrations vary along the cochlea following systemic applications. As a result, it has not yet been established whether aminoglycoside concentration gradients exist in ST perilymph after systemic applications. With the development of techniques capable of measuring drug gradients along ST [Mynatt et al., 2006], we were able to study the distribution of gentamicin in ST perilymph of the guinea pig after systemic application.

\section{Materials and Methods}

\section{Study Groups and Experimental Design}

Pigmented guinea pigs weighing 343-520 g (mean $430 \mathrm{~g}$ ) of both genders from an in-house breeding colony were used in this study. All experimental procedures were approved by the animal studies committee of the University of Tübingen, Germany (HN3/08).

Animals were anesthetized intramuscularly with an anesthetic composed of fentanyl $0.025 \mathrm{mg} / \mathrm{kg}$ body weight (BW), midazolam $1.0 \mathrm{mg} / \mathrm{kg} \mathrm{BW}$ and medetomidine $0.2 \mathrm{mg} / \mathrm{kg} \mathrm{BW}$. Throughout the experiment one third of the initial dosing was regularly injected intramuscularly as a supplemental dose. The ventilation of the animals was supported with $\mathrm{O}_{2}$. Heart rate and blood $\mathrm{pO}_{2}$ were monitored with a pulse oximeter (Surgivet; Smiths Medical, Grasbrunn, Germany). The anesthetized animals were placed on a temperature-regulated heating pad, fixed in a head holder and kept at $37.5^{\circ} \mathrm{C}$ body temperature.

The animals were divided into 4 experimental groups, either receiving an intravenous infusion of $100(\mathrm{n}=4), 300(\mathrm{n}=5)$ or 600 $(\mathrm{n}=3) \mathrm{mg} / \mathrm{kg} \mathrm{BW}$ of gentamicin-sulfate $\left(40 \mathrm{mg} / \mathrm{ml}\right.$, Refobacin ${ }^{\circledR}$; Merck, Darmstadt, Germany), respectively, or a subcutaneous bolus injection of $300 \mathrm{mg} / \mathrm{kg} \mathrm{BW}(\mathrm{n}=3)$. The solutions were adjusted to physiological $\mathrm{pH}$ and intravenous solutions were continuously administered for $3 \mathrm{~h}$ via a jugular venous polyethylene tube catheter (inner diameter: $0.28 \mathrm{~mm}$, outer diameter: $0.61 \mathrm{~mm}$; Neolab, Heidelberg, Germany). At $3 \mathrm{~h}$ after the start of intravenous gentamicin infusion, perilymph was aspirated from ST of the right ear to allow measurement of gentamicin concentration. For perilymph sampling, the apex of the cochlea was exposed by a ventrolateral surgical approach and the surface of the cochlear apex was made hydrophobic by applying a thin layer of cyanoacrylate adhesive (Histoacryl; Aesculap, Tuttlingen, Germany) followed by twopart silicone glue (WPI, Berlin, Germany). A total of 10 sequential apical perilymph samples (approximately $1 \mu$ leach) were collected over a period of 10-20 min using calibrated microcapillaries (Brand, Wertheim, Germany). The 1st sample represents perilymph from the apical regions and the 4th and 5th samples represent perilymph from the basal regions of ST. Later samples contain mainly CSF that has passed through ST after entering via the cochlear aqueduct. The preparation of the animal and the sequential apical sampling technique have been described in detail elsewhere [Mynatt et al., 2006; Salt et al., 2006; Plontke et al., 2008]. The same perilymph collection procedure was then repeated in the opposite 
(left) cochlea of the same animal $2 \mathrm{~h}$ after the termination of the gentamicin infusion, i.e. $5 \mathrm{~h}$ after the start of the intravenous gentamicin infusion.

Blood serum was collected by nail clipping under deep anesthesia. Serum samples were obtained before starting the application of gentamicin or within $10 \mathrm{~min}$ after starting the intravenous or subcutaneous application. The 2 nd blood sample was drawn 30 min after the start of the gentamicin application and was then repeated every $60 \mathrm{~min}$. The blood sample drawn at the end of the experiment from animals that were subjected to subcutaneous gentamicin application was obtained with cardiac cannulation.

\section{Perilymph Sample Analysis}

Concentration of gentamicin in perilymph samples was quantified with a fluorescence polarization immunoassay (TDX SLX Analyzer; Abbott Diagnostics, Wiesbaden, Germany). The sample fluid was diluted in an assay buffer with a ratio of 1:79. The sensitivity (limit of quantification, LOQ) was $0.27 \mu \mathrm{g} / \mathrm{ml}$. Perilymph of untreated animals was analyzed as controls. Blood serum samples were quantified with the same method.

\section{Computer Simulations}

As the cross-sectional area of ST decreases progressively from base to apex, drug kinetics in ST could be influenced by the varying fluid volumes. We therefore interpreted the measured sample data with an established finite element model of the inner ear fluids that incorporates the varying cross-sectional areas of the guinea pig fluid compartments with distance and all the adjacent tissue compartments of the ear. The program calculates concentrations along the length of ST with entry kinetics from blood either uniform along the length of the scala or varying from base to apex. Entry by other routes, such as via the endolymph, can also be calculated. In addition, the program simulates the apical sequential sampling procedure used here, allowing calculated sample values to be compared with measured data. The program (version 3.080) is available to be downloaded from http://oto.wustl.edu/cochlea/.

\section{Results}

\section{Gentamicin Serum Levels}

With intravenous injections the serum concentration of gentamicin increased within minutes of the start of infusion and increased progressively during the 180 -min injection (fig. 1, solid symbols). When injection stopped, gentamicin began to slowly decline. With subcutaneous bolus applications, serum concentration increased more rapidly and the highest concentration was measured at approximately 60 min after the injection (fig. 1, open symbols).

\section{Gentamicin Distribution in ST Perilymph after Intravenous Application}

Figure 2 shows the gentamicin concentrations of 10 sequentially collected samples from the cochlear apex. In all cases the initial samples were of the highest concentration and later samples were consistently lower in concen-

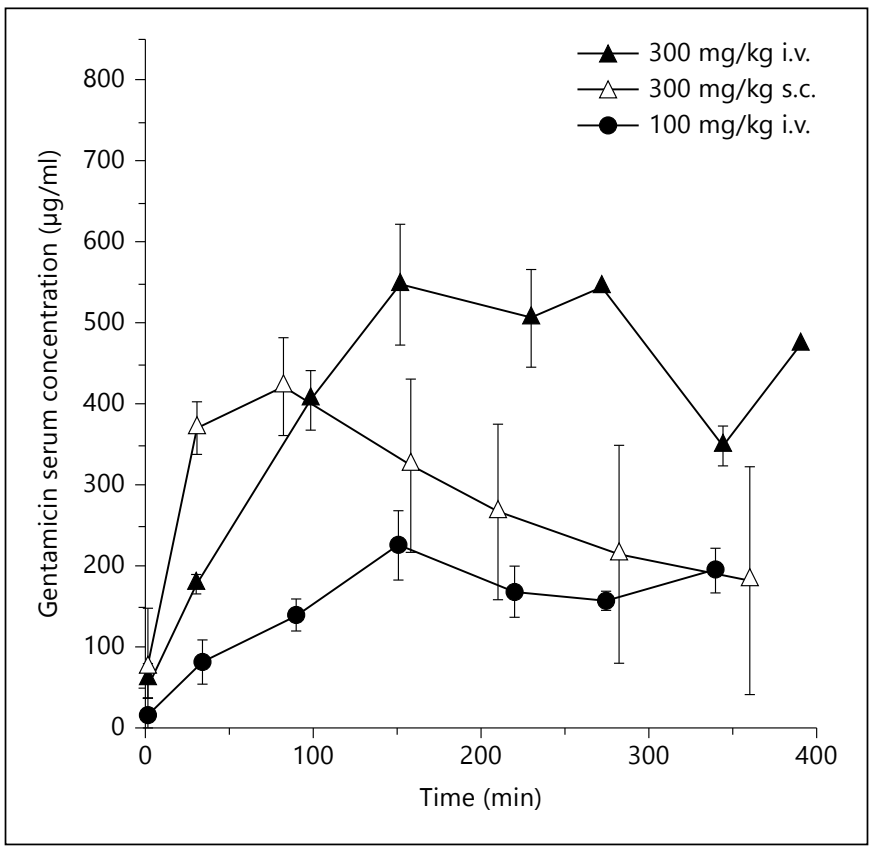

Fig. 1. Gentamicin serum concentrations with intravenous and subcutaneous applications. With continuous intravenous application peak values were observed at $150 \mathrm{~min}$ after start of application. After the termination of application (180 $\mathrm{min})$ serum values started to decline slowly. With single subcutaneous injections (300 mg/ $\mathrm{kg} \mathrm{BW}$ ) peak concentrations in serum were observed approximately $60 \mathrm{~min}$ after application. For the same dose applied, higher peak concentrations were measured with intravenous applications compared to the subcutaneous paradigm. Error bars indicate SD.

tration. In this paradigm, the 1 st sample contained perilymph from the apical regions of ST, regions which are sensitive to low-frequency stimuli. Samples numbered 2-4 were derived from more basal parts (higher-frequency regions) of ST. Subsequent samples consist of CSF (which may itself contain gentamicin) that has passed through ST, accumulating or losing gentamicin from adjacent tissues and compartments during its passage according to the prevailing concentration gradients. These data therefore demonstrate that there is an apical-basal gradient of gentamicin in ST following intravenous administration.

The first series of samples was taken $3 \mathrm{~h}$ after the start of the intravenous infusion, i.e. immediately after the 3-hour infusion was stopped. In the low-dose group (100 $\mathrm{mg} / \mathrm{kg} \mathrm{BW}$ ) the mean value of the 1 st samples of three experiments was in the range of the LOQ of the assay $(0.27 \mu \mathrm{g} / \mathrm{ml})$, whereas in samples $2-10$ gentamicin concentration was below $L O Q$. The mean $( \pm S D)$ value for the 1st sample was $25.18 \pm 2.64 \mu \mathrm{g} / \mathrm{ml}$. Systemic administra- 


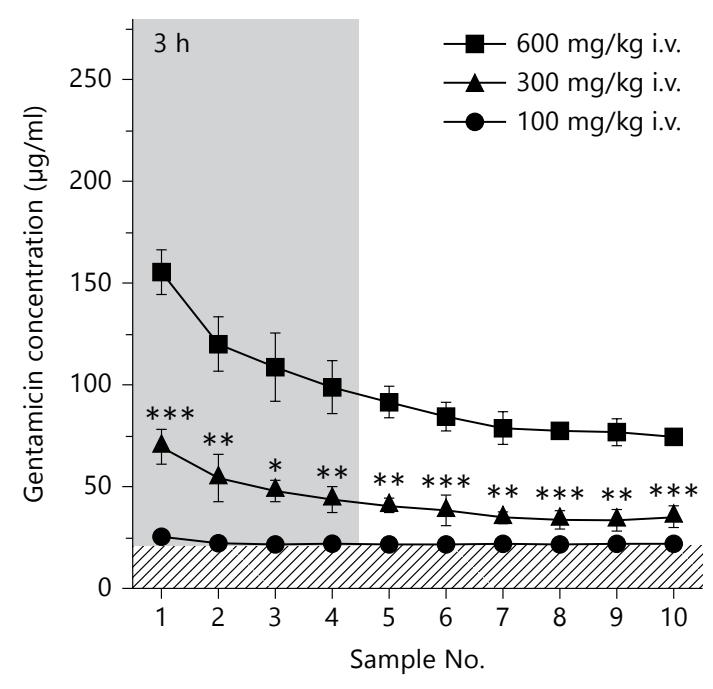

Fig. 2. Gentamicin gradients in ST perilymph revealed by sequential sampling from the cochlear apex after continuous intravenous application $3 \mathrm{~h}$ (left) and $5 \mathrm{~h}$ (right) after the start of drug application. The first 4 samples (gray area) correspond to perilymph from different regions of ST. Sample 1 (originating from apical perilymph) always contained higher gentamicin concentration than sample 4 (originating from the basal turn) demonstrating the existence of an apical-basal concentration gradient along the scala. This is completely opposite to the basal-apical gradients that were measured in previous experiments following local (RWM) applications [Plontke

tion of 300 and $600 \mathrm{mg} / \mathrm{kg}$ BW provided concentrations above the LOQ in all samples. In the $300 \mathrm{mg} / \mathrm{kg}$ BW group, the 1st sample showed a mean peak concentration of $69.65 \pm 8.50 \mu \mathrm{g} / \mathrm{ml}$ gradually declining to $40.69 \pm 3.49$ $\mu \mathrm{g} / \mathrm{ml}$ in the 5 th and $35.37 \pm 5.34 \mu \mathrm{g} / \mathrm{ml}$ in the 10 th sample. The mean peak value (apical sample) in the $600 \mathrm{mg} /$ $\mathrm{kg}$ BW experimental group was $155.53 \pm 10.96 \mu \mathrm{g} / \mathrm{ml}$ in the first, declining to $91.73 \pm 7.78$ and $74.32 \pm 3.55 \mu \mathrm{g} / \mathrm{ml}$ in the 5th and 10th samples, respectively.

The second series of samples was taken from the opposite cochlea of the same animal $5 \mathrm{~h}$ after the start of intravenous infusion, i.e. $2 \mathrm{~h}$ after the infusion had stopped. The intracochlear concentration increased even after the intravenous application was stopped and higher concentrations of gentamicin, mostly well above the LOQ, were measured in ST perilymph (fig. 2 right). Similar to the 3-hour data, the highest concentrations were observed in the 1st samples (apical origin) with concentration gradually declining for following samples originating more basally. With $100 \mathrm{mg} / \mathrm{kg}$ the first sample was $57.81 \pm 10.00$ $\mu \mathrm{g} / \mathrm{ml}$, the 5 th sample was $31.19 \pm 7.67 \mu \mathrm{g} / \mathrm{ml}$ and the 10 th sample was below the LOQ. ST drug levels in the other 2

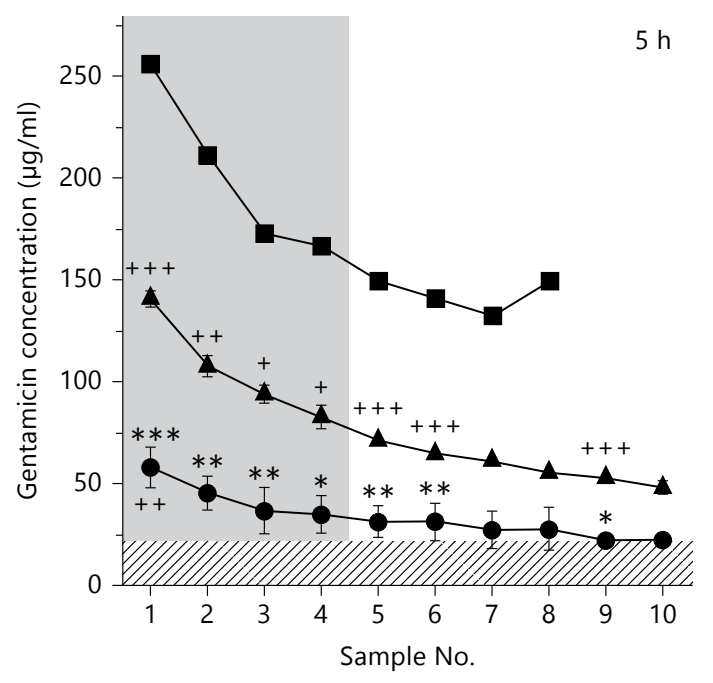

et al., 2007]. Subsequent samples (No. 5-10) contain CSF (which itself may contain gentamicin) that has passed through ST. The measured gentamicin levels in these later samples can be explained by repartitioning of the drug from adjacent cochlear compartments back into ST. With increasing dose higher concentrations were observed in perilymph at both 3 and $5 \mathrm{~h}$. Error bars indicate SD. The pale shaded area at the lower part of each graph indicates LOQ. ${ }^{* * *} \mathrm{p}<0.001,{ }^{* *} \mathrm{p}<0.01,{ }^{*} \mathrm{p}<0.05$ : for comparison of doses at one sampling time; ${ }^{+++} \mathrm{p}<0.001,{ }^{++} \mathrm{p}<0.01,{ }^{+} \mathrm{p}<0.05$ : for comparison of same doses but between the 3 - and 5-hour sampling times.

dosage groups (i.e. 300 and $600 \mathrm{mg} / \mathrm{kg} \mathrm{BW}$ ) were higher, corresponding to the higher total amount of gentamicin given. Peak concentrations in the $300 \mathrm{mg} / \mathrm{kg} \mathrm{BW}$ group were measured in the 1st sample (mean $140.79 \pm 4.00 \mu \mathrm{g} /$ $\mathrm{ml}$ ), declining to $71.01 \pm 0.61 \mu \mathrm{g} / \mathrm{ml}$ in the 5 th and $48.05 \pm$ $3.31 \mathrm{mg} / \mathrm{ml}$ in the 10th sample. With $600 \mathrm{mg} / \mathrm{kg}$ BW gentamicin concentration was determined in one 5-hour experiment only and a similar concentration gradient was found (1st sample $256.12 \mu \mathrm{g} / \mathrm{ml}$ and 5th sample $149.22 \mu \mathrm{g} /$ $\mathrm{ml})$. In all experiments the data are consistent with higher concentrations in the apical turns of the cochlea, with amounts varying in a dose-dependent manner.

The intravenous infusion protocol allowed for delivery of gentamicin with a low variability of absolute gentamicin concentrations in ST perilymph. The statistical significant differences between the different dose groups at each sampling time are indicated in figure 2 (Student's $t$ test, MS-EXCEL for Mac 2011, version 14.3.2). The 100mg group was not analyzed statistically at $3 \mathrm{~h}$, since most samples were below the LOQ. Similarly, the $600 \mathrm{mg} / \mathrm{kg}$ BW dosing regimen at $5 \mathrm{~h}$ was not analyzed statistically, since only a single data set from one cochlea was available. 


\section{Gentamicin Distribution in ST Perilymph after} Subcutaneous Application

Figure 3 shows the gentamicin concentrations in ST perilymph samples after a single subcutaneous bolus injection in each animal. Lower drug concentrations were found in the perilymph after subcutaneous applications compared to the intravenous protocol with the same dose $(300 \mathrm{mg} / \mathrm{kg} \mathrm{BW})$. At both 3- and 5-hour sampling times, concentration was higher in the initial sample and declined in following samples, again demonstrating a prominent apex-to-base distribution of gentamicin similar to that observed after intravenous infusion. The first samples contained the highest gentamicin concentrations $(59.40 \pm 8.46 \mu \mathrm{g} / \mathrm{ml}$ at $3 \mathrm{~h}$ and $81.32 \pm 17.62 \mu \mathrm{g} / \mathrm{ml}$ at $5 \mathrm{~h})$ with the subsequent samples showing a decline in concentration towards the basal parts of the cochlea (5th sample $31.19 \pm 7.14 \mu \mathrm{g} / \mathrm{ml}$ and 10th sample $23.56 \pm 1.43$ $\mu \mathrm{g} / \mathrm{ml}$ at $3 \mathrm{~h}$, and 5 th sample $48.84 \pm 12.94 \mu \mathrm{g} / \mathrm{ml}$ and 10 th sample $32.72 \pm 8.66 \mu \mathrm{g} / \mathrm{ml}$ at $5 \mathrm{~h}$ ).

\section{Data Analysis and Interpretation with Computer Simulations}

Measured gentamicin concentrations were analyzed using our finite element computer model considering pharmacokinetically important factors for gentamicin uptake into and distribution within the cochlea. The model incorporates concentration-driven exchange between the blood and the cochlear fluid compartments as well as exchange between cochlear scalae and adjacent tissues and passive diffusion along each scala. We used the program to predict sequential sample values for the 3- and 5-hour collection time points for a constant plasma level that approximated the level achieved in vivo. Entry into the cochlea fluids was calculated using the following two paradigms:

(1)Entry was assumed to occur directly from blood into ST perilymph. Exchange between blood and ST perilymph was defined as a basal turn entry half-time and an adjustment that allowed the entry rate to vary linearly as a function of distance along the scala. This allowed basal and apical entry rates to be varied independently, with graded entry for points in between, to best fit the measured curves.

(2)Entry into ST perilymph was assumed to occur indirectly via endolymph [Li and Steyger, 2011]. In this analysis, a single variable defined the half-time of entry from blood into endolymph, with a uniform entry half-time along the length of the cochlea. A second variable defined half-times of exchange between endolymph and the organ of Corti and between the organ of Corti and ST perilymph.

Cochlear Gentamicin Gradients following Systemic Applications

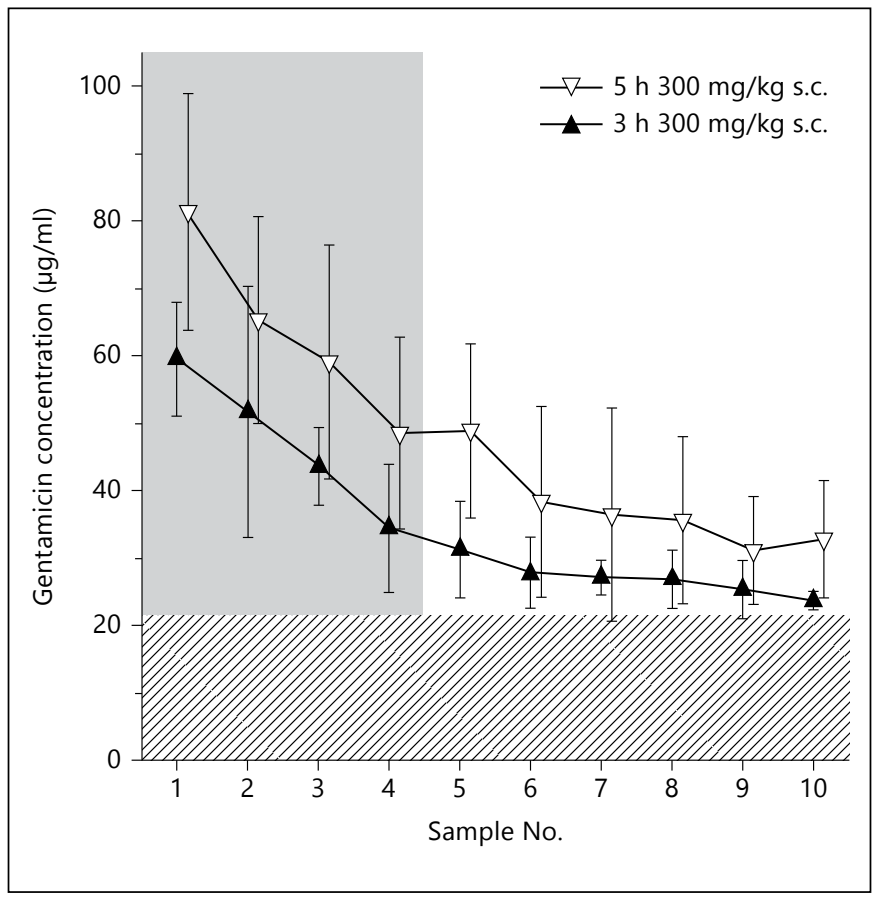

Fig. 3. Gentamicin gradients in ST perilymph after subcutaneous bolus injections. Although lower drug concentrations were measured in the perilymph after subcutaneous applications compared to the intravenous protocol with the same dose $(300 \mathrm{mg} / \mathrm{kg} \mathrm{BW})$, gentamicin distribution indicated an apical-basal gradient as in the continuous intravenous infusion protocol. Gray area: samples originating from ST perilymph. Pale gray shaded area at the bottom of the graph indicates the LOQ.

For each condition, the procedure of apical sampling was simulated using the sample volumes and collection times derived from the appropriate data set. A best fit to the data was determined by systematically varying pharmacokinetic parameters in a manner to minimize the sum of squares of differences between measured and calculated sample values [Plontke et al., 2002].

When entry into ST was assumed to be directly from blood, the influence of varying entry rates along the length of ST on samples taken from the apex are demonstrated in figure 4 . These curves are calculated for fast (200-min entry half-time) and slow (2,000-min entry half-time) kinetics in the basal and apical turns, with graded entry between these rates along the scala length. Samples are calculated for $300 \mathrm{mg} / \mathrm{kg}$ dose with a total delivery time of $5 \mathrm{~h}$. When entry occurs at similar rates for both apex and base (fig. 4, curves A and D) the calculated initial samples 1 and 2 (originating in the apex) are lower than samples 4 and 5 (originating in the basal turn). This is a result of the cochlear anatomy, built into the model, in which tis- 


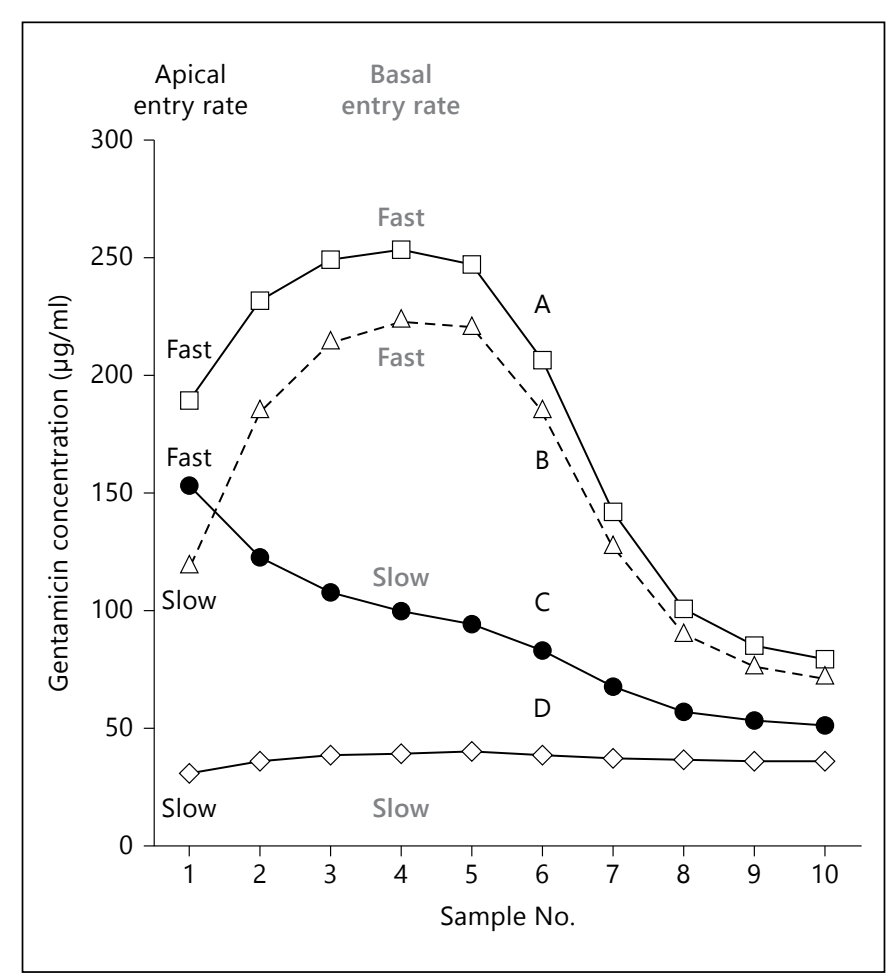

Fig. 4. Calculated sample concentration curves for four combinations of entry kinetics from blood to ST perilymph. 'Fast' entry indicates a 200-min entry half-time and 'Slow' entry indicates a 2,000min entry half-time at the location. Curve A: curve for fast entry throughout ST. Initial samples (originating from the apex) are lower than sample 4 (originating from the basal turn), as solute losses to adjacent compartments are more significant at the apex, where ST cross-section is small. Curve B: curve for fast entry in the basal turn and slow entry in the apical turn with entry rates graded in between. The difference between sample 1 (from the apex) and sample 4 (from the base) is even greater. Curve C: curve for slow entry in the basal turn and fast entry at the apex with rates graded in between. Sample 1 (from the apex) is now higher than sample 4 (from the base). Curve D: curve for slow entry throughout ST. The curve is comparable to curve A, but lower. If direct gentamicin entry into ST was assumed, sample concentration curves comparable to the measured data (fig. 2, 3) could only be achieved with a higher entry rate at the apex relative to the base (i.e. curve $\mathrm{C}$ with solid symbols).

sue and fluid compartments adjacent to ST (spiral ligament, spiral ganglion, organ of Corti, scala vestibuli, etc.) are proportionately larger at the apex (where ST crosssection is relatively small), compared to the base (where ST cross-section is substantially larger). For the condition with fast entry at the base and slow entry at the apex (fig. 4, curve B), the difference between apical and basal samples is even greater. In contrast, when entry is fast at the apex and slow at the base (fig. 4, curve C), the initial sample is high but subsequent samples have progressive-
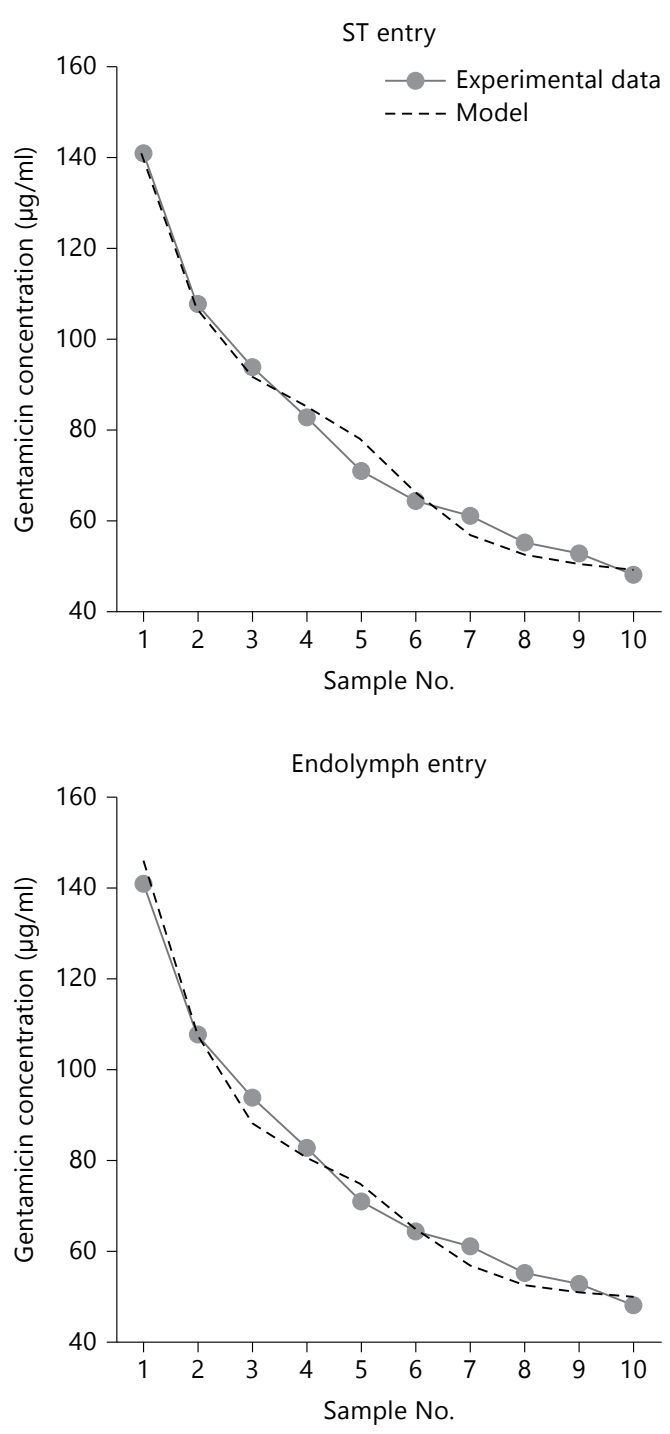

Fig. 5. Gray lines: mean gentamicin concentration in sequential perilymph samples after continuous intravenous application $(300 \mathrm{mg} /$ $\mathrm{kg} \mathrm{BW}) 5 \mathrm{~h}$ after start of drug application (gray, from fig. 2). Black lines show calculated sample values. Top: gentamicin entry from blood into ST with slower entry kinetics at the base than at the apex of the cochlea. Bottom: gentamicin reaching ST by an endolymphatic route with uniform entry rates along the cochlea. In this case the faster kinetics in apical ST perilymph is due to the far smaller ST cross-sectional area in apical turns compared to the base, while endolymph remains relatively uniform in cross-section with distance.

ly lower concentrations. This curve is comparable to the sample data we obtained experimentally.

Examples of simulations fitted to the average sample data at $5 \mathrm{~h}$ following $300 \mathrm{mg} / \mathrm{kg} \mathrm{BW}$ intravenous infusion are shown in figure 5 . In the upper panel, the data were 
fitted based on direct gentamicin entry into ST. In order to generate a higher concentration in the 1st sample (apical perilymph) compared to later samples (samples 4 and 5 originating from perilymph of the basal turn), it was necessary to use much faster entry into apical compared to basal regions, as described above. The best fit here was obtained with a half-time of entry into the basal turn of 2,675 min and a 10.8-times faster entry into apical regions (corresponding to a shorter half-time of $249 \mathrm{~min}$ ). Thus the data could be explained by approximately 10-times faster entry kinetics in the apical cochlear regions compared to the base. However, the lower panel of figure 5 also shows the analysis in which gentamicin entry into ST occurred indirectly via the endolymph. In this case the calculated sample values resulted from entry into endolymph with a 110-min half-time (uniform throughout the length of the cochlea) and communication half-times between endolymph and the organ of Corti and organ of Corti to perilymph of $10 \mathrm{~min}$ each (also uniform along the cochlea). The calculated samples again closely fit the measured data, in this case accounted for by the differences in volume relationships between endolymph and perilymph in the basal and apical turns. Endolymph is relatively uniform in the cross-sectional area along the cochlea while ST is substantially larger in the basal turn than in apical turns. This results in faster kinetics in the smaller apical regions of ST when in communication with endolymph. These analyses show there may be more than one explanation for the faster entry of gentamicin into the apical regions of ST in this study.

\section{Discussion}

For all applied doses and for both intravenous and subcutaneous applications, we found consistent apicalbasal concentration gradients of gentamicin in the perilymph of ST. This observation is in contrast to measurements after local application of gentamicin or others substances (e.g. TMPA and dexamethasone) to the RWM, in which substantial concentration gradients from the base to the apex were found [Mynatt et al., 2006; Plontke et al., 2007, 2008]. The basal-apical gradient in ST after extracochlear (intratympanic, RWM) application can be explained by the uptake of the drug via the RWM and the oval window, with drug spreading predominantly by diffusion in the perilymph of the ST from the base to the apex, and local communication between scalae in all segments of the cochlea combined with elimination (clearance) of drug from the perilymph,

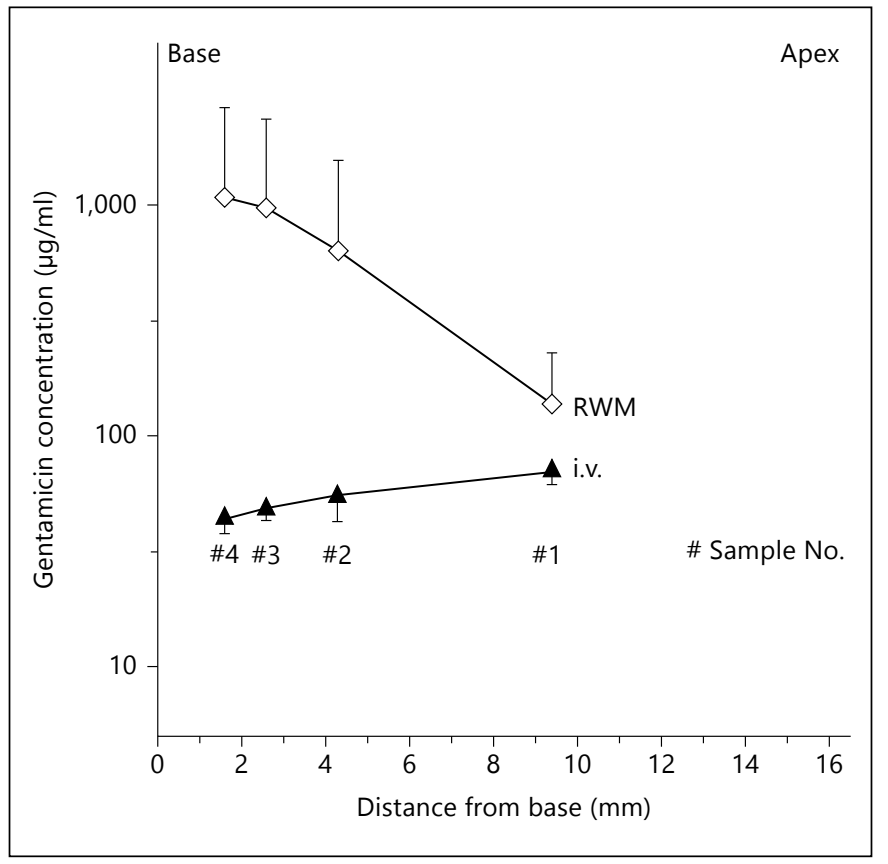

Fig. 6. Mean gentamicin concentrations in ST in sequential apical samples taken from ST after $3 \mathrm{~h}$ of continuous intravenous application (300 mg/kg BW group from fig. 2 left, full symbols) compared with the mean gentamicin concentrations after continuous irrigation of the RWM for $3 \mathrm{~h}$ (historical data from a previous study of our group [Plontke et al., 2007]). The distance along ST plotted is that of the midpoint of the estimated region of origin for $1-\mu$ l samples (half the sample volume apical and half the volume basal to the location). Note logarithmic scale.

as supported by previous anatomic and physiological studies [Saijo and Kimura, 1984; Salt et al., 1991; Plontke et al., 2002; King et al., 2011; Salt et al., 2012]. In addition, a substantially lower variability in the measured intracochlear drug concentrations was found after systemic compared to RWM application [Plontke et al., 2007] (fig. 6).

Absolute perilymph concentrations of gentamicin were time and dose dependent. The higher gentamicin concentrations measured at $5 \mathrm{~h}$ compared to $3 \mathrm{~h}$ ( $2 \mathrm{~h}$ after infusion finished compared to immediately after infusion) for all 3 dosing regimens indicates that gentamicin continues to enter and to accumulate in the cochlea even after the termination of systemic intravenous drug application. Taking samples from the two cochlea of the same animal at different time points helps to decrease the interindividual variability and to reduce the number of animals needed.

Gentamicin gradients after systemic application have not been quantitatively measured in previous cochlear 
pharmacokinetic studies. For the interpretation of the observed apical-basal gradients in ST, computer simulations were used that allowed the variation of entry rates with otherwise fixed parameters (e.g. diffusion coefficient of the drug, dimensions of the scalae and intercompartment communications). The analysis showed that for a bloodto-perilymph entry route the apical-basal gradient in ST could only be explained by higher entry rates in the apex compared to the basal turns of the cochlea (fig. 4,5 ). The simulations also demonstrated that the sample data could alternatively be explained by gentamicin entering perilymph indirectly from the blood, via the endolymph. A uniform entry into endolymph would result in faster kinetics in apical turns due to the smaller cross-sectional area of ST relative to the base, leading to the observed apical-basal gentamicin gradient in ST (fig. 5). However, from our measurements and interpretations with a computer model it cannot be concluded by which route gentamicin enters the cochlear fluids from the blood.

Former studies investigating entry of gentamicin into the cochlea after systemic application also revealed two alternative ways of trafficking of which one emphasized the perilymph route and the other supported the access via the blood labyrinthine barrier into the endolymph. Entry through the porous bony structure of the modiolus (ST and scala vestibuli) and through the capillaries of the spiral ligament is a possible pathway for drug entering into perilymph as suggested by anatomic studies [Shepherd and Colreavy, 2004; Rask-Andersen et al., 2006]. Tran Ba Huy et al. [1981, 1986] measured a higher loading of the perilymph compared to the endolymph and suggested gentamicin access to the sensory hair cells across their basolateral membranes, which are in contact with perilymph. A route from perilymph into endolymph was also indicated in a study showing that a fluorescent gentamicin probe could enter the organ of Corti and the outer hair cells following RWM application [Zhang et al., 2010].

The second route was suggested by trafficking of gentamicin through the strial blood labyrinthine barrier into the endolymph. This hypothesis is supported by a number of studies showing permeation of gentamicin through TRPV 1 and TRPV4 cation channels and through mechanotransduction channels that are located predominantly in the apical membranes of the hair cells and contact the endolymphatic fluid [Karasawa et al., 2008; Wang and Steyger, 2009; Alharazneh et al., 2011; Vu et al., 2013]. Inhibitors of endocytosis at the basolateral membranes of the hair cells had no influence on gentamicin entry [Alharazneh et al., 2011]. Uptake of gentamicin through nonspe- cific cation channels (TRPA1) into outer hair cells of mice was also shown in ex vivo studies, but the exact subcellular location of these channels has not been determined so far [Stepanyan et al., 2011]. Transport across channels in the apical membranes of the hair cells can also be considered as a mechanism for clearance from endolymph, resulting in higher aminoglycoside concentrations in the perilymph compared to low concentrations in the endolymph as shown in previous studies [Tran Ba Huy et al., 1981].

Evidence for a predominant stria-endolymph access is supported by a recent study [Li and Steyger, 2011]. During systemic intravenous application, uptake of a fluorescent-labeled gentamicin probe into the organ of Corti was demonstrated even when accumulation of fluorescentlabeled gentamicin in ST perilymph was prevented by simultaneously perfusing ST with artificial perilymph. When ST was perfused with the same probe without systemic application only weak uptake was shown in the organ of Corti, providing evidence that the gentamicin could not enter the endolymph from ST. Both experiments give support to the idea of stria-endolymph trafficking of gentamicin, at least in short-term observations.

Gentamicin is toxic to sensory hair cells [Wu et al., 2002; Rybak and Ramkumar, 2007]. Differences in toxicity to vestibular and cochlear hair cells cannot necessarily be inferred from such pharmacokinetic findings as described in this article, since it is likely that susceptibility to gentamicin of cochlear and vestibular hair cells and cochlear hair cells in different regions is not equal. In vivo and in vitro studies showed increased toxicity of gentamicin in the high-frequency basal regions compared to the low-frequency region in the apical turns of the cochlea [Wu et al., 2002]. Following systemic applications to guinea pigs, gentamicin was initially found in the outer hair cells of all cochlea turns, but became more localized in cells of the basal turn with increasing survival times [Imamura and Adams, 2003]. Temporal bone studies of humans treated with aminoglycosides showed predominantly basal turn pathology, including loss of hair cells and spiral ganglion cells [Sone et al., 1998]. Our study implies that apical hair cells might be more resistant to gentamicin even in the presence of higher gentamicin concentrations and support the hypothesis/findings of heterogeneous sensory hair cell populations along the tonotopic axis of the cochlea. This observation is in accordance with previous studies showing that hair cell protection in the apical turn could be explained with a tonotopic variation in conductance of the mechanotransduction channels [Ricci et al., 2003], or a reduced susceptibility for free radicals in this region [Sha et al., 2001]. 


\section{Acknowledgments}

This work was supported in part by BMBF grants 0313844B and 0314103 (S.P.) and by NIH/NIDCD grant DC01368 (A.S.). The technical contributions of Sina Bässler and Claudia Glunz are appreciated.

\section{Disclosure Statement}

Stefan K. Plontke is a consultant for Otonomy, Inc., San Diego, Calif., USA. Alec N. Salt is a member of the scientific advisory board of Otonomy, Inc. This work was not sponsored by Otonomy.

\section{References}

Alharazneh A, Luk L, Huth M, Monfared A, Steyger PS, Cheng AG, Ricci AJ: Functional hair cell mechanotransducer channels are required for aminoglycoside ototoxicity. PloS One 2011;6:e22347.

Beck C, Schmidt CL: 10 years of experience with intratympanally applied streptomycin (gentamycin) in the therapy of Morbus Ménière. Arch Otorhinolaryngol 1978;221:149-152.

-Chia SH, Gamst AC, Anderson JP, Harris JP: Intratympanic gentamicin therapy for Ménière's disease: a meta-analysis. Otol Neurotol 2004;25:544-552.

- Fausti SA, Larson VD, Noffsinger D, Wilson RH, Phillips DS, Fowler CG: High-frequency audiometric monitoring strategies for early detection of ototoxicity. Ear Hear 1994;15:232239.

-Hoffer ME, Balough B, Henderson J, DeCicco M, Wester D, O'Leary MJ, Kopke R: Use of sustained release vehicles in the treatment of Ménière's disease. Otolaryngol Clin North Am 1997;30:1159-1166.

Igarashi M, Lundquist PG, Alford BR, Miyata $\mathrm{H}$ : Experimental ototoxicity of gentamicin in squirrel monkeys. J Infect Dis 1971; 124(suppl):S114-S124.

Imamura S, Adams JC: Distribution of gentamicin in the guinea pig inner ear after local or systemic application. J Assoc Res Otolaryngol 2003;4:176-195.

-Karasawa T, Wang Q, Fu Y, Cohen DM, Steyger PS: TRPV4 enhances the cellular uptake of aminoglycoside antibiotics. J Cell Sci 2008; 121:2871-2879.

King EB, Salt AN, Eastwood HT, O’Leary SJ: Direct entry of gadolinium into the vestibule following intratympanic applications in guinea pigs and the influence of cochlear implantation. J Assoc Res Otolaryngol 2011;12:741751.

Lange G: The intratympanic treatment of Ménière's disease with ototoxic antibiotics. A follow-up study of 55 cases (author's transl). Laryngol Rhinol Otol 1977;56:409-414.

Li H, Steyger PS: Systemic aminoglycosides are trafficked via endolymph into cochlear hair cells. Sci Rep 2011;1:159.

- Mynatt R, Hale SA, Gill RM, Plontke SK, Salt AN: Demonstration of a longitudinal concentration gradient along scala tympani by sequential sampling of perilymph from the cochlear apex. J Assoc Res Otolaryngol 2006;7:182193.
Plontke SK, Biegner T, Kammerer B, Delabar U, Salt AN: Dexamethasone concentration gradients along scala tympani after application to the round window membrane. Otol Neurotol 2008;29:401-406.

Plontke SK, Mynatt R, Gill RM, Borgmann S, Salt AN: Concentration gradient along the scala tympani after local application of gentamicin to the round window membrane. Laryngoscope 2007;117:1191-1198.

Plontke SK, Wood AW, Salt AN: Analysis of gentamicin kinetics in fluids of the inner ear with round window administration. Otol Neurotol 2002;23:967-974.

Pullens B, van Benthem PP: Intratympanic gentamicin for Ménière's disease or syndrome. Cochrane Database Syst Rev 2011;3:CD008234.

Rask-Andersen H, Schrott-Fischer A, Pfaller K, Glueckert R: Perilymph/modiolar communication routes in the human cochlea. Ear Hear 2006;27:457-465.

Ricci AJ, Crawford AC, Fettiplace R: Tonotopic variation in the conductance of the hair cell mechanotransducer channel. Neuron 2003; 40:983-990.

Rybak LP, Ramkumar V: Ototoxicity. Kidney Int 2007;72:931-935.

- Saijo S, Kimura RS: Distribution of HRP in the inner ear after injection into the middle ear cavity. Acta Otolaryngol 1984;97:593-610.

-Salt AN, Gill RM, Plontke SK: Dependence of hearing changes on the dose of intratympanically applied gentamicin: a meta-analysis using mathematical simulations of clinical drug delivery protocols. Laryngoscope 2008;118: 1793-1800.

- Salt AN, Hale SA, Plontke SK: Perilymph sampling from the cochlear apex: a reliable method to obtain higher purity perilymph samples from scala tympani. J Neurosci Methods 2006;153:121-129.

Salt AN, Hartsock JJ, Gill RM, Piu F, Plontke SK: Perilymph pharmacokinetics of markers and dexamethasone applied and sampled at the lateral semi-circular canal. J Assoc Res Otolaryngol 2012;13:771-783.

Salt AN, King EB, Hartsock JJ, Gill RM, O'Leary SJ: Marker entry into vestibular perilymph via the stapes following applications to the round window niche of guinea pigs. Hear Res 2012; 283:14-23.

Salt AN, Ohyama K, Thalmann R: Radial communication between the perilymphatic scalae of the cochlea. I. Estimation by tracer perfusion. Hear Res 1991;56:29-36.
Schuknecht HF: Ablation therapy for the relief of Ménière's disease. Laryngoscope 1956;66: 859-870.

-Sha SH, Taylor R, Forge A, Schacht J: Differential vulnerability of basal and apical hair cells is based on intrinsic susceptibility to free radicals. Hear Res 2001;155:1-8.

-Shepherd RK, Colreavy MP: Surface microstructure of the perilymphatic space: implications for cochlear implants and cell- or drug-based therapies. Arch Otolaryngol Head Neck Surg 2004;130:518-523.

-Sone M, Schachern PA, Paparella MM: Loss of spiral ganglion cells as primary manifestation of aminoglycoside ototoxicity. Hear Res 1998; 115:217-223.

-Stepanyan RS, Indzhykulian AA, Velez-Ortega AC, Boger ET, Steyger PS, Friedman TB, Frolenkov GI: TRPA1-mediated accumulation of aminoglycosides in mouse cochlear outer hair cells. J Assoc Res Otolaryngol 2011; 12:729-740.

Tran Ba Huy P, Bernard P, Schacht J: Kinetics of gentamicin uptake and release in the rat. Comparison of inner ear tissues and fluids with other organs. J Clin Invest 1986;77: 1492-1500.

Tran Ba Huy P, Manuel C, Meulemans A, Sterkers $\mathrm{O}$, Amiel C: Pharmacokinetics of gentamicin in perilymph and endolymph of the rat as determined by radioimmunoassay. J Infect Dis 1981;143:476-486.

-Vu AA, Nadaraja GS, Huth ME, Luk L, Kim J, Chai R, Ricci AJ, Cheng AG: Integrity and regeneration of mechanotransduction machinery regulate aminoglycoside entry and sensory cell death. PloS One 2013;8:e54794.

Wagner N, Caye-Thomasen P, Laurell G, BaggerSjoback D, Thomsen J: Cochlear hair cell loss in single-dose versus continuous round window administration of gentamicin. Acta Otolaryngol 2005; 125:340-345.

-Wang Q, Steyger PS: Trafficking of systemic fluorescent gentamicin into the cochlea and hair cells. J Assoc Res Otolaryngol 2009;10:205-219.

Wu WJ, Sha SH, Schacht J: Recent advances in understanding aminoglycoside ototoxicity and its prevention. Audiol Neurootol 2002;7: 171-174.

Zhang Y, Zhang R, Dai C, Steyger PS, Yu Y: Comparison of gentamicin distribution in the inner ear following administration via the endolymphatic sac or round window. Laryngoscope 2010;120:2054-2060. 